\title{
Critical Analysis of the Application of Fuzzy Logic in Renewable Energy Systems
}

\author{
Mohammed Y. Ghadi ${ }^{1}$, Fadi Sakka ${ }^{1}$, Ahmed Al Nakeeb ${ }^{1}$, Tamara al Shloul ${ }^{2}$ \\ ${ }^{1} \mathrm{HBMSU}$, Academic City, Dubai, UAE \\ ${ }^{2}$ Al Ain University, Abu Dhabi, UAE
}

\begin{abstract}
This study describes the effectiveness of applying Fuzzy controller into the renewable energy storage system for better efficiency. Different small size power generators need to be initially started up in order to fulfil the demand of power at the rush hours. V2G (Vehicle to grid) technology is an interface of bidirectional electrical grid which allows electric vehicles to take energy from the mesh. The calculation for the power requirement of the battery is initiated for identifying the charging load. When it comes to power management for the electric vehicles (EVs), information technology plays a vital role for the V2G framework. The delivery of power request to the aggregate of EVs through the aggregator is done with the help of sending a signal from the RTO/ISO. The load is generated with the help of huge as well as continuously running units of power generation and gradable EVs. In V2G optimization, lowering the overall operational cost may be achieved by using wind power as well as using the grid.
\end{abstract}

Keywords - V2G framework, power management, renewable energy

\section{Introduction}

In the field of power and energy, the use of fossil fuels has become intensively heavy and this factor is

DOI: 10.18421/TEM104-16

https://doi.org/10.18421/TEM104-16

Corresponding author: Mohammed Y. Ghadi, HBMSU, Academic City, Dubai, UAE

Email: M.Ghadi@hbmsu.ac.ae

Received: 16 August 2021.

Revised: 23 September 2021.

Accepted: 04 October 2021.

Published: 26 November 2021.

(c) BY-NC-ND (C) 2021 Mohammed Y. Ghadi et al; published by UIKTEN. This work is licensed under the Creative Commons Attribution-NonCommercial-NoDerivs 4.0 License.

The article is published with Open Access at www.temjournal.com guiding the world towards the practical use of nonconventional energy sources in daily life. Different sources of renewable energy such as wind energy, solar energy and ocean energy evolved in order to fulfil the human needs. Among the different sources of renewable energy, extraction as well as practical use of wind energy is easy compared to other renewable energy sources. Besides, extraction of wind energy is dependent on the natural characteristics. Due to this, we cannot fully rely on the wind energy as an alternative to conventional energy sources. As a result, people are considering developing as well as applying mobile powers for running the world in the future. This study discusses the different renewable energy power systems and the use of Fuzzy logic for managing the energy sources.

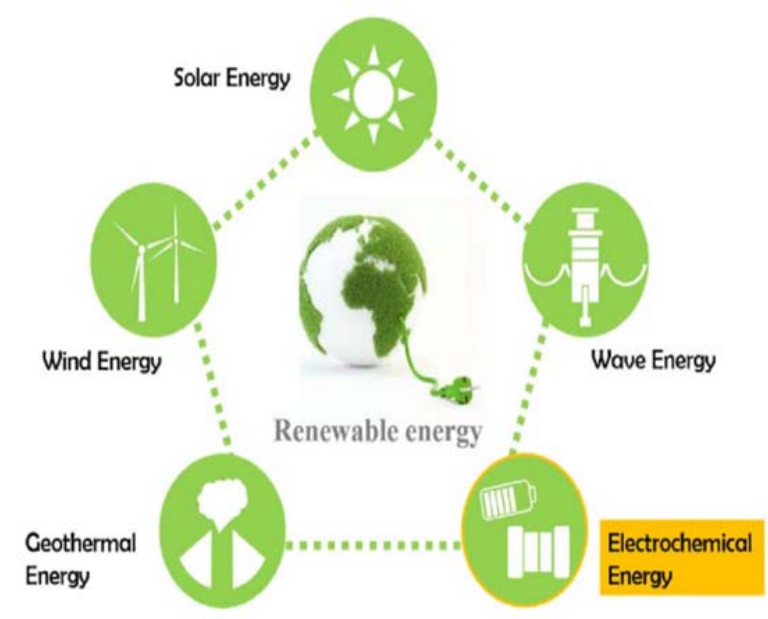

Figure 1. Different sources of renewable energy system

\section{V2G (Vehicle to Grid) Concept}

The main idea of $\mathrm{V} 2 \mathrm{G}$ can be described as charging EVs with the help of the power grid at the time of low power demand the battery capacity can be utilized more efficiently. V2G turns EV charging from electrical demand by the vehicle as well as feeding power to the grid when it demands supply of power [1]. At different hours, daily load alters greatly. Different small size power generators need to be initially started up in order to fulfil the 
demand of power at the rush hours. Incorporating the V2G concept, power systems can be designed in more stable as well as reliable way along with lowering the involvement of cost.

During the daytime, aggregate EVs can deliver back power in order to save the rush hour load. On the other hand, at night time, gradable EVs are being charged for the power grid and can be considered as loads [4]. Due to this, aggregate EVs are able to balance the low load during off-peak hours. Thus, integration of $\mathrm{V} 2 \mathrm{G}$ concept helps for the high demand of electricity in the day time when all industries as well as plants are running in their full capacity and during the night time when the waste of electricity takes place. A conceptual graph is provided below which describes the regular amount of load with or without the EVs.

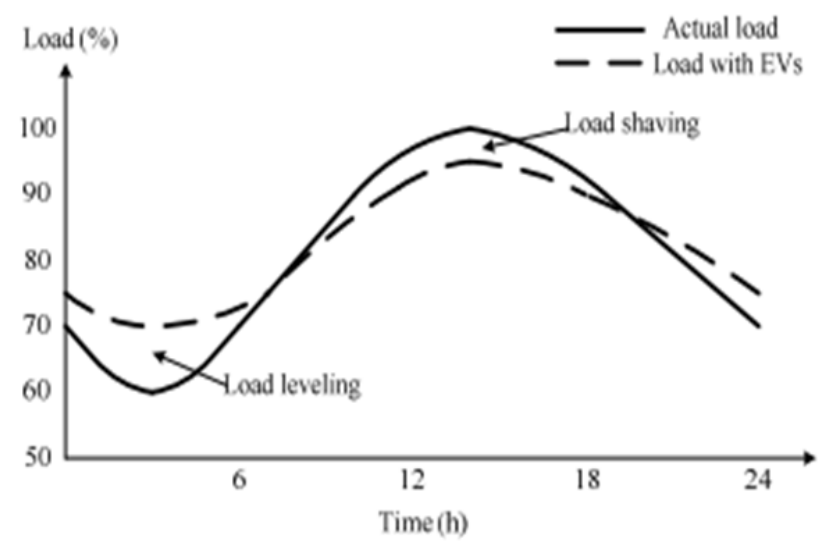

Figure 2. Daily loads without or with EVs multilevel vehicle to grid structural framework

Vast use of fossil fuel results in increasing environmental issues such as air pollution, as well as the problem of global warming, which can impact the human life severely. Due to this, developers take step for using electric vehicles (EV) in the near future for reducing the rate of emission and save the planet Earth.

V2G (Vehicle to grid) technology is an interface of bi-directional electrical grid which allows electric vehicles to take energy from the mesh as well as putting it back to the mesh [1]. There are a total of three types of gradable EVs present in the current market such as plug in hybrid EV as well as extended range EV and battery EV. Among these types, battery EVs are able to serve as portable bi directional power plants and they are able to conserve power at the time of parking as well as deliver power when necessary with the help of power convertor [3].

In the V2G model considered as cutting edge type of circulation systematic matrix, networking path between micro grids along with vitality sources driven by renewable energy is joined in an effective way. Overall systematic process related to vehicle and grid connection has been incorporated in the model for showing generation of load and connection with power.

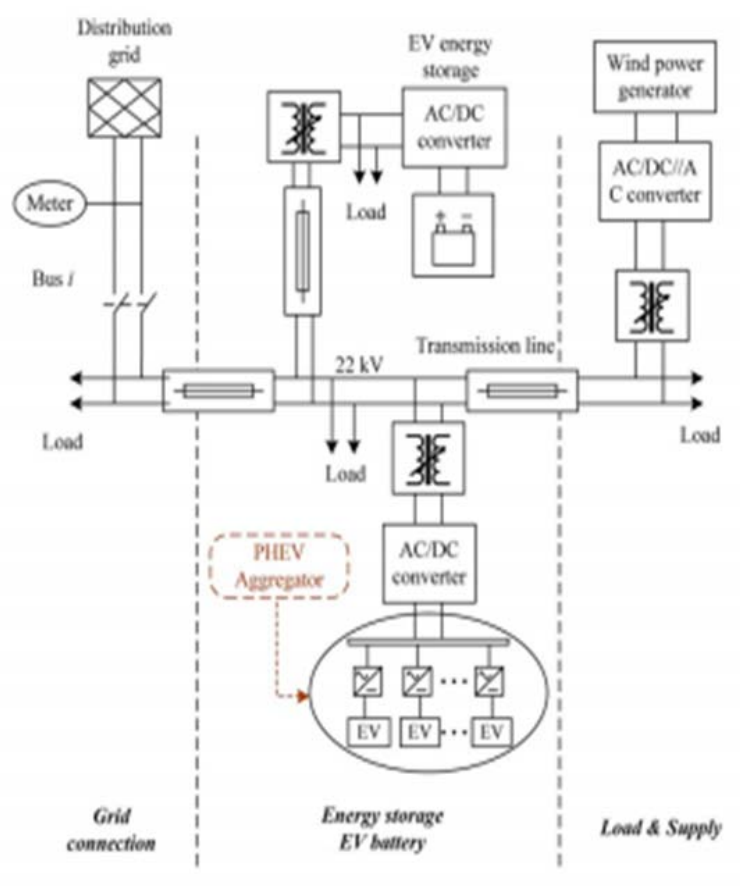

Figure 3. V2G dynamic regulation model diagram incorporating wind power

Different types of charging framework are incorporated with the EVs in terms of a system related to test power [10]. The frameworks are looking forward to cover the 20 percent of the total district. The EV transport quantity can be determined by $\mathrm{n}_{\mathrm{x}}=\operatorname{int}\left(\mathrm{r}_{\mathrm{EV}} \mathrm{n}_{\mathrm{b}}\right)=6$.

In this equation, $n_{b}$ is referred to aggregate number of transport and it is the dimensional EVs entry level. The calculation for the power requirement of the battery is initiated for identifying the charging load [5]. Calculation for identifying the power requirement as well as charging load for EVs is done with the help of the following equations:

$$
\begin{aligned}
& \varepsilon_{T}=\sum_{i=1}^{N_{\text {TE }}} \frac{\left(S O C_{i, d d}-S O C i, \text { int }\right) E C_{i}}{n} \\
& =\frac{\mu\left(S O C_{n d}\right)-\mu\left(S O C_{\text {int }}\right)}{n} N_{E V}\left(\sum_{i=1}^{N_{\text {ES }}} E C_{h i}\right.
\end{aligned}
$$

The initial system on a chip is considered as to the Figure 3. configuration in order to prepare the whole circuit of the EV.

In this section of power management for the EVs, information technology plays a vital role for the V2G framework. The aggregation for huge number of EVs is responsible for gathering EVs as well as inclining them to maintain a certain level of power grid interaction [6]. Due to this, gradable electric vehicles are able to act as the load as well as the resources. 


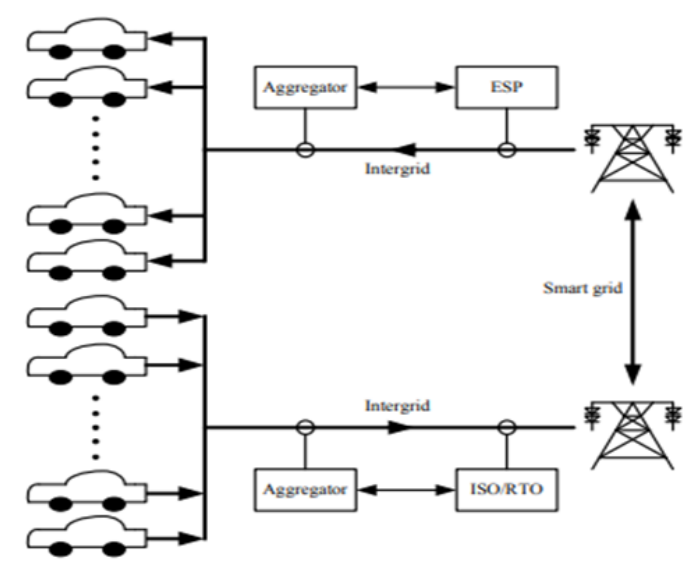

Figure 4. V2G structure for aggregate EVs

In the above figure it can be observed that, acting aggregate EVs can act as the source of load for the grid operator. Total produced load capacity by the aggregate EVs can impact the grid operator in terms of regional transmission organization (RTO) as well as independent system operator (ISO) [2]. The delivery of power request to the aggregate of EVs through the aggregator is done with the help of sending a signal from the RTO/ISO to the bulk power distribution system. At the time of acting as a load, aggregate EVs also send request of charging to the ESP (energy service provider) with the help of aggregator. The whole process of aggregating EVs and functioning can be observed and understood by the proposed framework in Figure 4.

\section{Vehicle to Grid Networking Connection}

Administration process of energy is generally intended to take advantages of electric vehicles which are basically administered into five subcategories. This is for executing key multi efficient into a strategic command plan. Divisional structure of gathering is generally controlled effectively by example of driving which includes available battery network along with time of flight.

Ultimate rate of process related to charging along with power support into model of V2G and mode on the basis of idle and driving are major perspectives in the context of grid networking connection procedure [3]. Categorisation of grid network along with electric vehicles is generally based on severe considerations which are described below to gather significant information related to V2G networking grid.

$$
\begin{aligned}
& g_{I}=\left\{E V_{i} \mid S O C_{l, \text { min }} \leq S O C_{E V_{i}} \leq S O C_{l, \text { max }}\right. \\
& T_{R_{m, \min }} \leq t_{R_{m}} E V_{i} \leq t_{R_{m_{\text {max }}}} \\
& \left.r_{F, E V_{i}}=1 \text { for } V 2 G \text { set }\right\} \\
& t_{R_{m, V_{i}}}=t_{d, E V_{i}}-t+\frac{\left(S O C_{e d, E V_{i}}-S O C_{E V_{i}}(t)\right) E_{E V_{i m a x}}}{P_{E V_{i, \max }}} \\
& p_{x_{i, k}}=p_{x_{i, m x}} \text { if } E V_{i} \in \text { Group I }
\end{aligned}
$$

\section{Optimization of V2G Concept}

\section{a. Analysing the Cost Emission}

Normally, the base load is generated with the help of huge as well as continuously running units of power generation and gradable EVs. In this case, the cost involvement for the large size power generation systems is also very high. Due to this, developers consider incorporating micro generating units along with gradable EVs in order to lower the cost involvement. Generally, in the case of V2G power system, various types of costs are involved in operations. These costs include fuel cost as well as start-up and shut down cost in addition to the maintenance cost. [4]. Optimization of the function of fitness for the cost emission can be determined with the help of the below given equation:

$$
\begin{aligned}
\min T C= & w_{c} \times(F u e l+\text { Start }- \text { up })+w_{c} \times \text { Emission } \\
= & \sum_{i=1}^{N} \sum_{t=1}^{H}\left[w_{c}\left(F C_{i}\left(P_{i}(t)\right)+S C_{i}\left(1-I_{i}(t-1)\right)\right)\right. \\
& \left.+w_{c}\left(\psi_{i} E C_{i}\left(P_{i}(t)\right)\right)\right] I_{i}(t)
\end{aligned}
$$

In the above questions, $P_{i}(t)$ denotes the power output of $i^{\text {th }}$ unit at the time $t$. The functions of fuel cost as well as emission and start up of "I" unit is denoted by $\mathrm{FC}_{\mathrm{i}}, \mathrm{EC}_{\mathrm{i}}$ and $\mathrm{SC}_{\mathrm{i}}$ respectively. The total number of units is denoted by $\mathrm{N}$ in the equation. Scheduling hours is stated as $\mathrm{H}$.

\section{b. V2G optimization}

In V2G optimization, lowering the overall operational cost for supply of power by the wind power as well as by the grid are the major areas of focusing towards the cost optimization for the system [4]. The overall operating cost of the system can be determined by the below given formula:

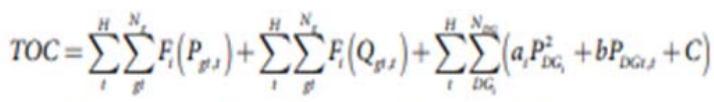

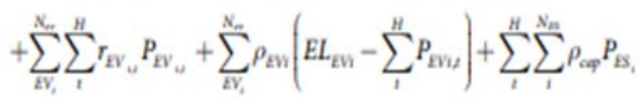


This objective function of operating cost analysis can be further simplified with the help of some other functions which are provided below:

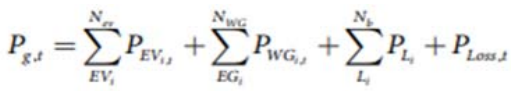

$$
\begin{aligned}
& P_{E V, \text { min } \leq P E V_{i}}(t) \leq P_{E V \text {,max }} \\
& 0 \leq E_{E V_{i=1}}+\int \rho E V_{i}(t) d t \leq E_{E V_{i-2}} \\
& \int p E V_{i}(t) d t=E_{E V_{1-2}}-E_{2 V_{i .}} \\
& S O C_{\min } \leq S O C_{\mathrm{id}}(t) \leq S O C_{\max } \\
& \operatorname{SOC}_{i d}(H) \leq S O C_{\text {finat }}
\end{aligned}
$$

\section{V2G aggregation}

The aggregation of $\mathrm{V} 2 \mathrm{G}$ system is used for giving incident parameter and indication to the market. The systematic energy management is penetrated for the use of EVs and is managed into 5 collectives to carry out the command plan in a multi effective manner [7]. The five collectives are: coordinate charging, V2G power support, idle as well as driving mode and utmost charging rate.

Utmost rate of charging is one of the main aspects of V2G system. Minimizing the load on the electric network and making the charging procedure quick for the V2G system in order to increase the overall efficiency. Coordinate charging collective helps for the charging procedure of the overall aggregate EVs in a single go. On the other hand, delivery as well as storing the power to the grid at the time of parking as well as running time is the consideration for driving mode under V2G system.

The system on a chip for the battery which is available locally and the time of flight are the example of driving which controls the collective divisions of the V2G aggregation [8]. Categorization of EVs is done by following the base functions which are provided below:

$$
\begin{aligned}
& g_{t}=\left\{E V_{i} \mid S O C_{l, \min } \leq S O C_{E V_{i}} \leq S O C_{l, \max }\right. \\
& T_{R_{n+\min }} \leq t_{\mathrm{R}_{\mathrm{a}}} E V_{i} \leq t_{\mathrm{R}_{\mathrm{ana}}} \\
& \left.r_{F, E V_{i}}=1 \text { for } V 2 G \text { set }\right\} \\
& t_{R_{\min }}=t_{d, E V_{i}}-t+\frac{\left(S O C_{e d, E V_{i}}-S O C_{E V_{i}}(t)\right) E_{E V_{i, e n}}}{P_{E V_{i, a w}}} \\
& p_{x_{i, j}}=p_{x_{i n a}}, \text { if } E V_{i} \in \text { Group } I \\
& \text { if } P_{x, k}>\sum_{i=1}^{i=N_{\xi^{i}}} P_{x_{i, m a x}}
\end{aligned}
$$

V2G aggregation directs for the transmission of information by the EV to the aggregator in terms of functioning of the whole system. The information technology integrated within the V2G system helps managing that information. There are some challenges for the aggregation process of EVs such as system operator interface, various modes of charging as well as different charging locations.

Huge incorporation of EVs creates some issues to the distribution network such as high traffic into the feeders as well as loss of power continuously. Due to this, the system operator considers the aggregator as an important agent for the overall grid operation of power distribution. On the other hand, the system of transmission considers aggregator as load reservoir along with load generator [4]. In case of various modes of charging such as bi directional way, aggregator works as a source of regulation of electric charge as well as a system of spinning of electric charge. Charging EVs anytime anywhere is stated as the phenomenon of dumb charging. In this case, EV is controlled by the owner other than the aggregator. Manual EV charging procedure for on/off electric supply causes barrier to the charging process at the time of any emergency [9]. On the other hand, different charging locations such as public places as well as residential and charging stations are the sources of power for an EV.

\section{Results}

Management of electric energy with the help of an effective stochastic scheduling of EV is provided in this study. The speed of flowing wind varies rapidly in terms of V2G system integration or the EV. The variation of wind flow speed for both scenarios of with or without the V2G system incorporation is shown with the help of a graph below:

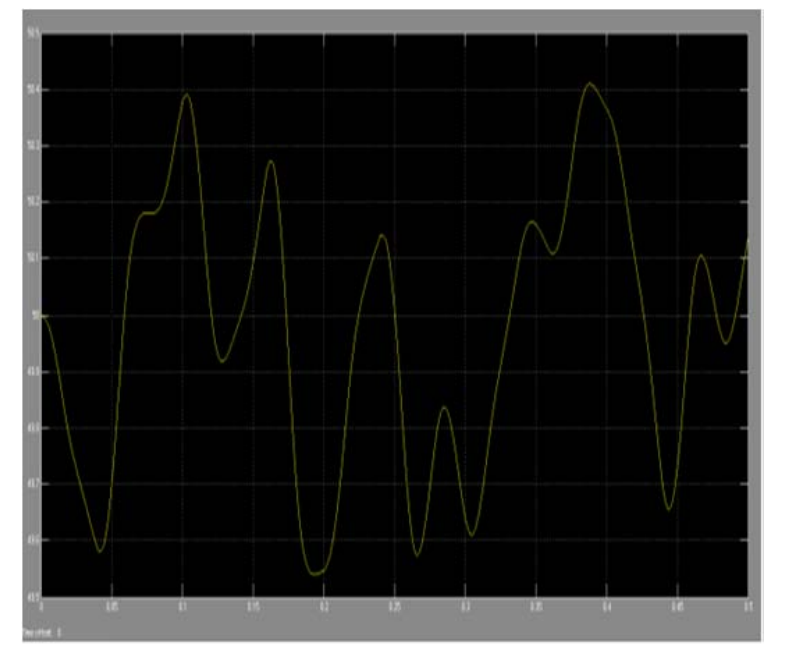

Graph 1(a). Flow speed of wind variation with respect to time without the V2G system 


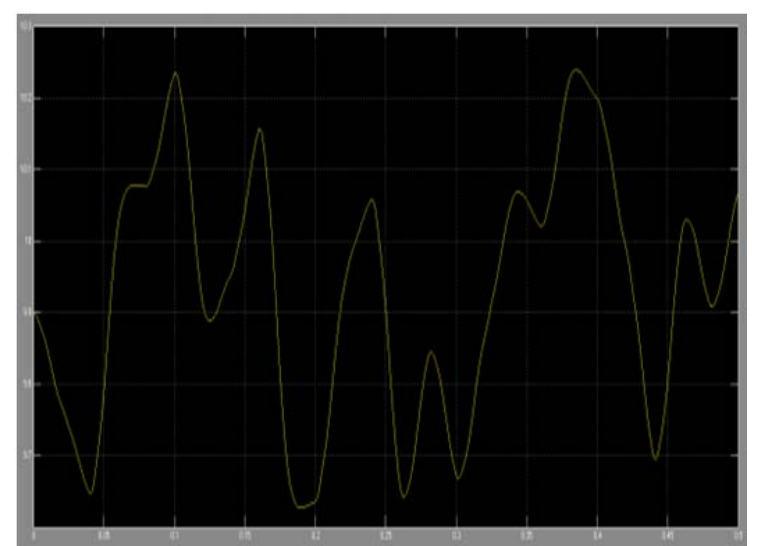

Graph 1(b). Variation of wind flow speed with respect to time with V2G system incorporation

The prediction of wind flow is not a suitable option for the operators because it is an environmental dependent factor. The speed of air is stochastic in nature due to this prediction of its characteristic is not possible for any specific time period. The overall capacity of the V2G system is bounded to $40 \mathrm{KW}$. At the beginning, the power of EV is used to the full extent and the utilization percentage is 100 percent. However, 75 percent of the overall utilization is used for this case though the EV rating is 100 percent. The variation of air power with respect to time without incorporating the system of $\mathrm{V} 2 \mathrm{G}$ is shown below with the help of a graph.

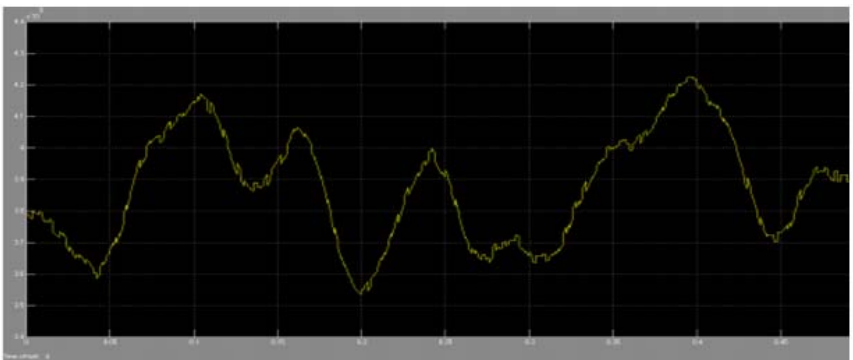

Graph 2. Variation of air power with respect to time with the V2G system

The fuzzification process of energy management included in proper scaling as well as mapping the input value, which transfers the value range of variables related to the input into the correlating universe of discourse. Effectual manipulation of arithmetic related to the fuzzy in the platform for getting the optimum result is known as FLC. In case of the FLC, it is possible to carry out the procedures easily as well as controlling the procedures without any hassle. Thus, the FLC is included in the energy storage facility for EV in order to control smoothly and finding out the satisfactory result. The finding results are provided below in terms of a graph.

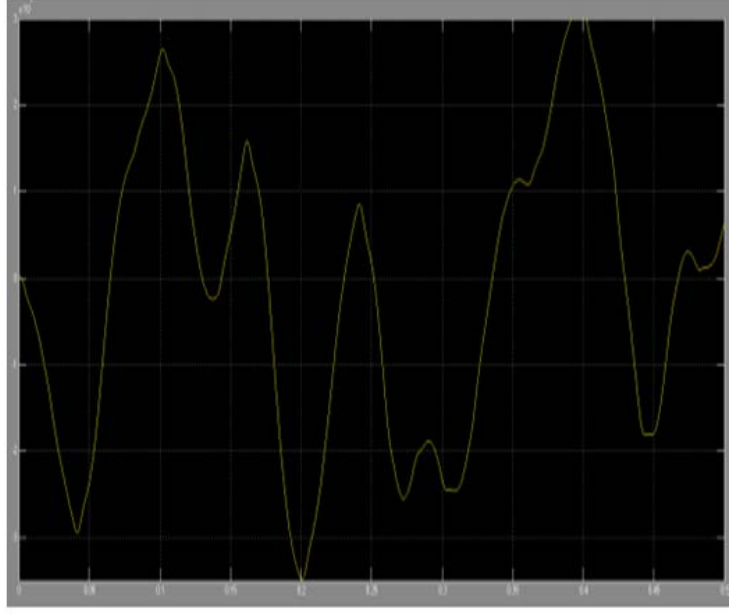

Graph 3. Variation of air control with respect to time with $V 2 G$ system incorporation

A schematic diagram for the Fuzzy logic controller is provided below in terms of understanding the basic structure of the controller.

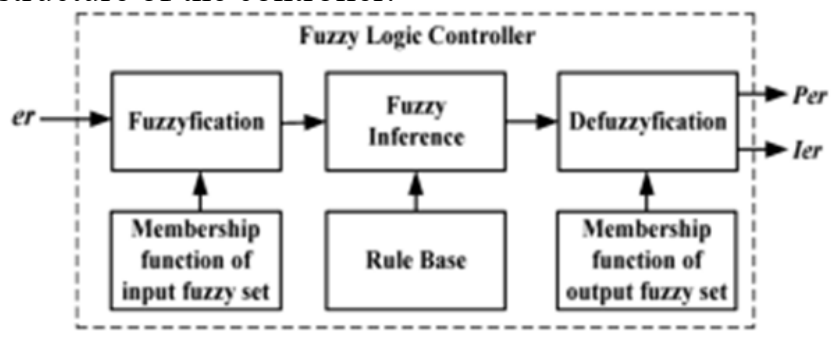

Figure 5. Fuzzy logic controller

Observed deviation in the frequency without or with the V2G controller system is provided below with the help of two graphs.

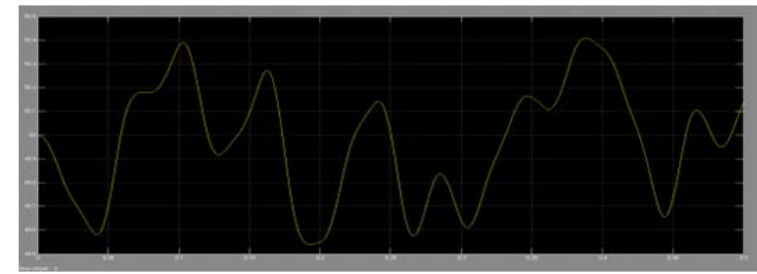

Graph 4(a). deviation in frequency without the V2G system

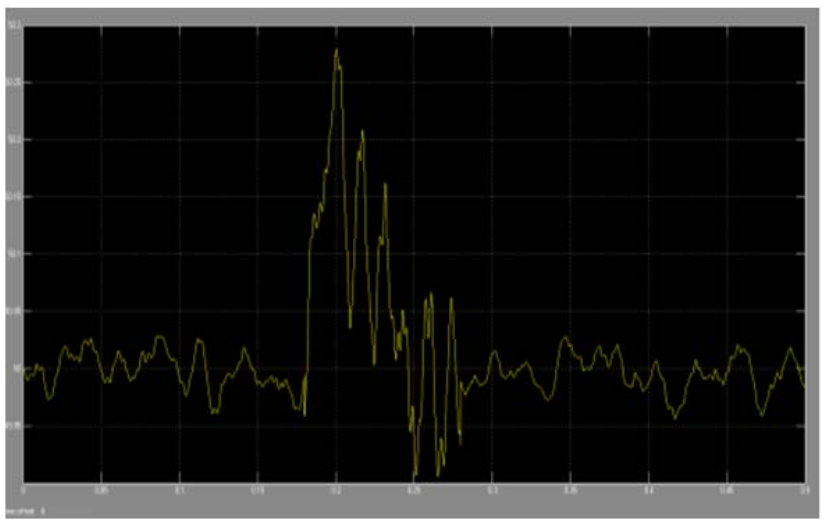

Graph 4(b). Deviation of frequency with V2G system incorporation 
The EVs which are not taken for consideration in order to meet the power grid requirements, can be used for regulating the frequency. On the other hand, the EVs which are not used for the frequency regulation are used for the required power at the rush instants. The frequency deviation with V2G control system strategy is given in 4(b).

Output of the total energy for the EV power application as 75 percent and 100 percent is provided in the Graph 5. and 6. The amount deficit power during the functioning of the grid is supplied by the EVs.

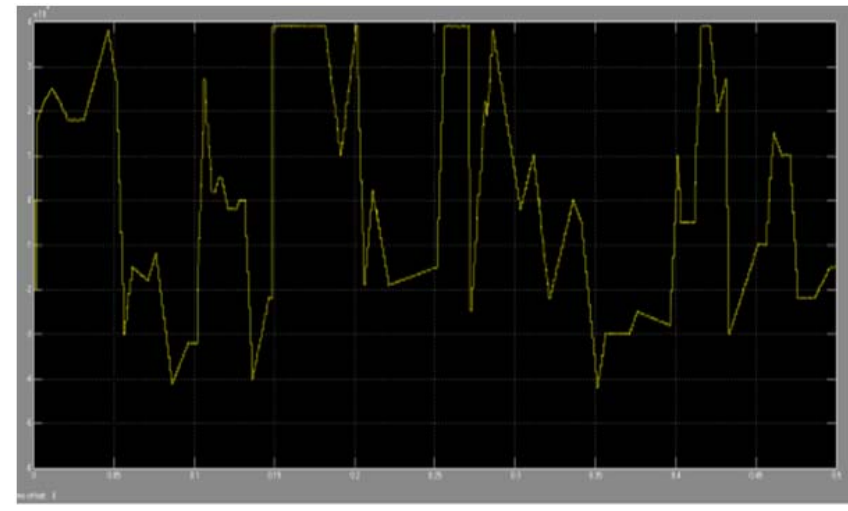

Graph 5. Power output of V2G system integration operation and 75 percent $E V$ utilization

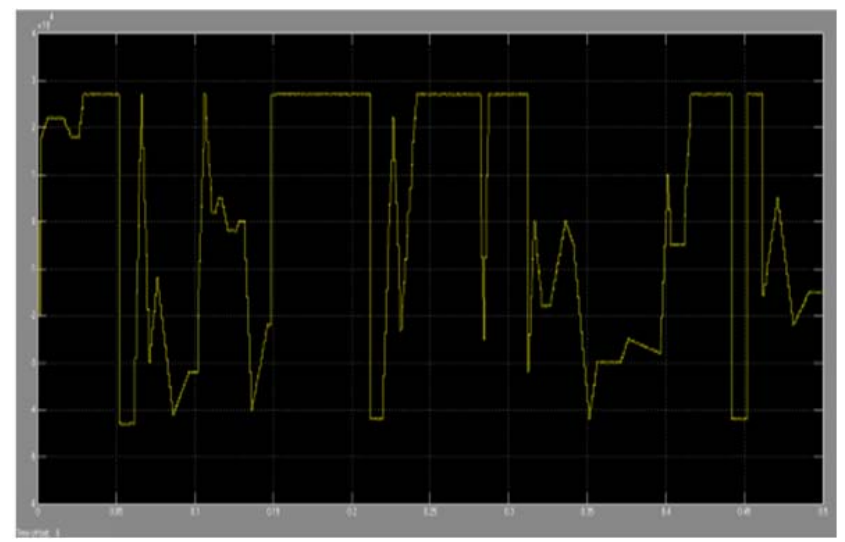

Graph 6. Power output of EV scheduling using V2G system and with 100 percent EV utilization

\section{Future Implication}

Incorporating the $\mathrm{V} 2 \mathrm{G}$ system practically into the renewable energy storage system enable us to manage the storage of renewable energy sources effectively. Apart from this, further developing the fuzzy logic controller and more effective way of incorporating this system into the practical field will be a turn up for the future generation in order to move towards the use of renewable energy sources and save the planet Earth.

\section{Conclusion}

Thus, it can be concluded that using Fuzzy logic controller to the energy storage system along with application of EVs can help for bettering our planet by reducing pollution from the fossil fuels in the future. Different sources of renewable energy such as wind energy, solar energy and ocean energy are discovered for fulfilling the energy requirements of our planet. Different small size power generators need to be initially started up in order to fulfil the demand of power at the rush hours. EVs are able to balance the low load during off-peak hours. Different types of charging frameworks are incorporated with the EVs in terms of a system related to test power. The delivery of power request to the aggregate of EVs through the aggregator is done with the help of sending a signal from the RTO/ISO.

\section{Reference}

[1]. Tan, K. M., Ramachandaramurthy, V. K., \& Yong, J. Y. (2016). Integration of electric vehicles in smart grid: A review on vehicle to grid technologies and optimization techniques. Renewable and Sustainable Energy Reviews, 53, 720-732.

[2]. Sah, B., Kumar, P., Rayudu, R., Bose, S. K., \& Inala, K. P. (2018). Impact of sampling in the operation of vehicle to grid and its mitigation. IEEE Transactions on Industrial Informatics, 15(7), 3923-3933.

[3]. Hu, X., Wang, K., Liu, X., Sun, Y., Li, P., \& Guo, S. (2018). Energy management for EV charging in software-defined green vehicle-to-grid network. IEEE Communications Magazine, 56(5), 156-163.

[4]. Han, S. \& Sezaki, K. (2015). Estimation of achievable power capacity from plug-in electric vehicles for V2G frequency regulation: Case studies for market participation. IEEE Transactions on Smart Grid, 2(4), 632-641.

[5]. Lam, A. Y., Leung, K. C., \& Li, V. O. (2015). Capacity estimation for vehicle-to-grid frequency regulation services with smart charging mechanism. IEEE Transactions on Smart Grid, 7(1), 156-166.

[6]. Alshahrani, S., Khalid, M., \& Almuhaini, M. (2019). Electric vehicles beyond energy storage and modern power networks: Challenges and applications. IEEE Access, 7, 99031-99064.

[7]. Kumar, A. P., Naresh, M., \& Prabhakar, P. (2015). Smart grid hybrid electric vehicles for road map development based on distributed dynamic pricing policy. International Journal of Innovative Technology, 3, 191-197.

[8]. Rahman, I., Vasant, P., Singh, B. S. M., \& AbdullahAl-Wadud, M. (2015). Swarm intelligence-based optimization for PHEV charging stations. In Handbook of research on swarm intelligence in engineering (pp. 374-405). IGI Global.

[9]. Aziz, M., Oda, T., \& Kashiwagi, T. (2015). Extended utilization of electric vehicles and their re-used batteries to support the building energy management system. Energy Procedia, 75, 1938-1943.

[10]. Petinrin, J. O., \& Shaabanb, M. (2016). Impact of renewable generation on voltage control in distribution systems. Renewable and Sustainable Energy Reviews, 65, 770-783. 